Postprint of pH-Controlled fermentation of strawberry waste as phenol solubilisation method Journal of Cleaner Production

Volume 266, 1 September 2020, 121924

DOI: https://doi.org/10.1016/j.jclepro.2020.121924

\title{
PH-CONTROLLED FERMENTATION OF STRAWBERRY WASTE AS PHENOL SOLUBILISATION METHOD
}

\author{
Antonio Serrano $^{1,2, *}$, Georgia Newton ${ }^{1}$, Bernabe Alonso-Fariñas ${ }^{3}$, Fernando G. Fermoso ${ }^{2}$, \\ Denys K. Villa-Gomez ${ }^{1}$
}

\footnotetext{
${ }^{1}$ School of Civil Engineering, The University of Queensland, Campus St. Lucia - AEB Ed 49, St Lucia, 4067, QLD, Australia

${ }^{2}$ Instituto de Grasa, Spanish National Research Council (CSIC). Ctra. de Utrera, km. 1, Seville, Spain.

${ }^{3}$ Departamento de Ingeniería Química y Ambiental, Escuela Técnica Superior de Ingeniería, Universidad de Sevilla, Camino de los Descubrimientos s/n, 41092 Seville, Spain.

*Corresponding author: Tel.: +61 (07) 3365 3857; E-mail: a.serranomoral@uq.edu.au
}

\section{Graphical Abstract}
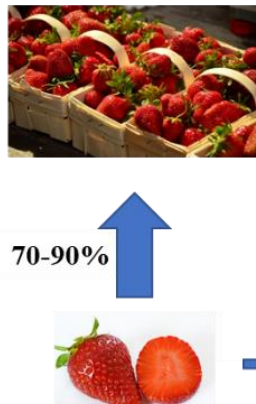

9 million tonnes/year

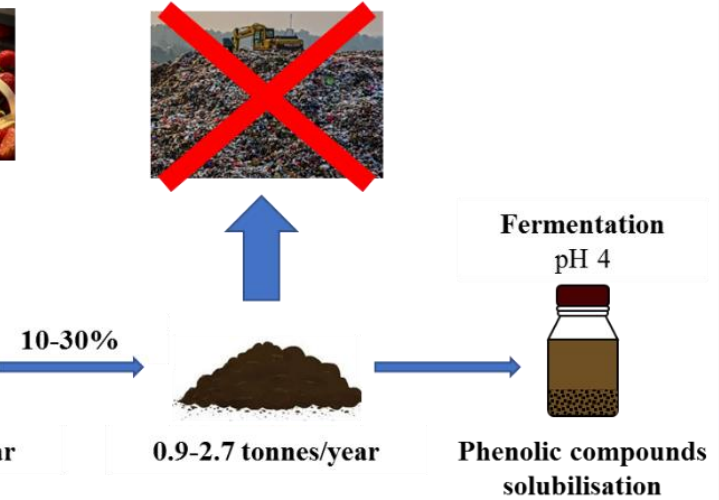

solubilisation

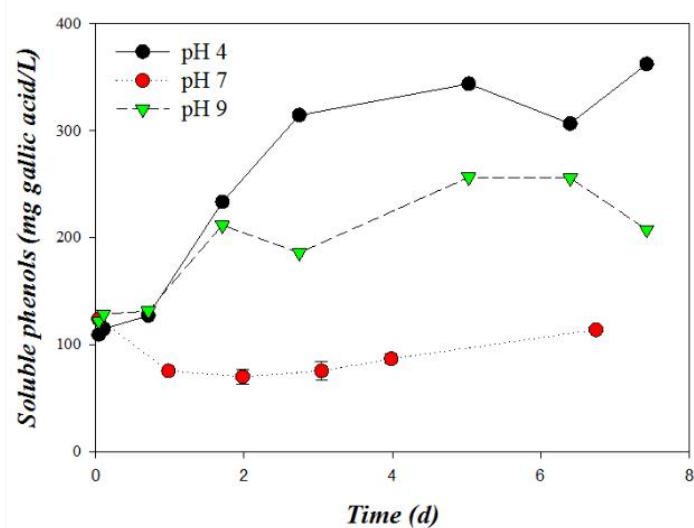

\section{Highlights}

- Soluble phenols were triplicated from initial concentration in reactors at $\mathrm{pH} 4$

- The process at $\mathrm{pH} 4$ consumed $96 \%$ less energy than thermal extractions of phenols 
- Operation at $\mathrm{pH} 9$ favoured the accumulation of acetic and propionic acids

\begin{abstract}
The present study aims to use $\mathrm{pH}$ as a control parameter for the accumulation of target compounds. Solubilisation of wasted strawberry through fermentation at different operational

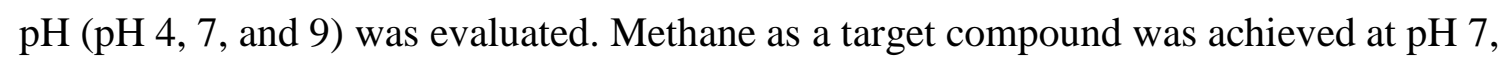
reaching a value up to $353 \pm 10 \mathrm{~mL} \mathrm{CH}_{4} / \mathrm{g}$ VS (VS, volatile solids). Operation at $\mathrm{pH} 9$ was hardly controlled due to the low $\mathrm{pH}$ of the substrate and the accumulation of VFA. $\mathrm{pH} 9$ resulted in the highest accumulation of VFA, mainly acetic acid. The operation at $\mathrm{pH} 4$ resulted in the inhibition of the biogas production, leading to the concentration of soluble phenols up to 3 times the initial concentration in the reactors. The concentrations of pelargonidin 3-glucoside and p-coumaric acid showed a significant increase at $\mathrm{pH} 4(\mathrm{p}=0.157$ and $\mathrm{p}=0.058$, respectively). Acidogenic fermentation could be a suitable method to solubilise bioactive compounds from wasted strawberries without the necessity of high-energy pretreatments. The low energy demand, i.e. 19 equivalent $\mathrm{kJ} / \mathrm{g}$ gallic acid, as well as the high phenol solubilization capacity, indicates that the acidogenic fermentation at $\mathrm{pH} 4$ it is a promising method for the recovery of phenols from wasted strawberry.
\end{abstract}

Keywords: anthocyanins; energy balance; fermentation; methane; soluble phenols; volatile fatty acids

\title{
1. INTRODUCTION
}

Strawberry is the most important berry crop worldwide, with an annual production of over 9 million tonnes in 2017. The production is concentrated in Mediterranean climate zones of China, USA, and Mexico, producing $40 \%, 17 \%$ and $7 \%$ of the global production respectively (FAOSTAT, 2018). An important percentage of this fruit is lost during 
agricultural production, postharvest handling and distribution, which could reach up to 10$30 \%$ of the total production (Warner et al., 2005). This huge volume of easily putrefactive waste entails a high polluting risk if not properly managed, such as uncontrolled global warming gas production, unpleasant smells, insect pests, or pollution of local watercourses from lixiviates (Siles et al., 2013). Management of these waste aligned with the circular economy concept includes resource recovery, reuse and recycling.

Due to its high content of fermentable sugars, strawberry waste can be used to produce valuable products such as volatile fatty acids (VFA) and methane (Fermoso et al., 2018). Bioactive compounds are also contained in strawberry waste (Giampieri et al., 2015; Giampieri et al., 2012; Rodríguez-Gutiérrez et al., 2019). The recovery of bioactive compounds is economically interesting due to their extensive applications in pharmacy, cosmetics or food industry (Baby et al., 2018; Zhang et al., 2008). However, these compounds are usually integrated into the lignocellulosic fibres of strawberry, making it necessary to first solubilise the fibres to extract the bioactive compounds (Rubio-Senent et al., 2013; Trujillo-Reyes et al., 2019). To achieve this, different methods have been previously proposed, which include hydrothermal treatments, electric pulses and microwave or ultrasound-assisted extraction (Fermoso et al., 2018). Most of these methods have been successfully applied for the extraction of bioactive compounds from other biomass sources, such as the olive mill solid waste (Rubio-Senent et al., 2013), fig leaves (Qin \& Chen, 2015) and pomegranate (Pan et al., 2012). However, most of these high-energy solubilisation methods might negatively affect some of the bioactive compounds present in the strawberry, such as the anthocyanins, which are highly thermosensitive (Jaster et al., 2018; Terefe et al., 2013).

As an alternative to the current solubilisation methods, different authors have proposed that acidogenic fermentation could be an alternative for releasing important 
bioactive compounds from biodegradable biomass sources (Girotto et al., 2017). Acidogenic fermentation is an integral step in anaerobic digestion where the fermentation metabolites such as VFA, ethanol or lactic acid are consumed by acetogenic and methanogenic microorganisms (Gu et al., 2018; Wu et al., 2015). If controlled conditions are met, full degradation of the organic matter to methane can be inhibited allowing the accumulation of these compounds. These conditions can be controlled by working at $\mathrm{pH}$ values outside that which is optimal for methanogenesis (Wheatley, 1990), but where hydrolytic and acidogenic activity still can occur (Zhang et al., 2009). For example, Cabrera et al. (2019) demonstrated that it is possible to accumulate phenolic compounds such as vanillin from olive mill solid waste through acidogenic fermentation at $\mathrm{pH} 5$. However, at this $\mathrm{pH}$, the methanogenic activity is not totally inhibited, so the degradation of phenolic compounds may still occur depending on the type of substrate.

The present study aims to evaluate the solubilisation of the wasted strawberry through acidogenic fermentation at different operational $\mathrm{pH}$, i.e. $\mathrm{pH} \mathrm{4,} \mathrm{7,} \mathrm{and} \mathrm{9.} \mathrm{The} \mathrm{processes} \mathrm{were}$ evaluated in terms of the inhibition of methane production, the accumulation of VFA and the accumulation of bioactive compounds such as phenolic acids and anthocyanins.

\section{MATERIALS AND METHODS}

\subsection{Anaerobic inoculum and wasted strawberry}

The anaerobic inoculum was obtained from the wastewater treatment plant of the XXXX brewery company (www.xxxx.com.au), located in Brisbane, Australia (-27.467634, 153.006357). Wasted strawberry was provided by Luvaberry® and SunnyRidge® berries farms. Both farms are located in the Caboolture region, Queensland, Australia. The wasted strawberry was blended prior to the experiments to improve its homogeneity and then frozen at $-10{ }^{\circ} \mathrm{C}$ to avoid undesirable fermentation processes. The characterization of the anaerobic inoculum and the wasted strawberry are shown in Table 1. 


\subsection{Experimental set-up and design}

Batch experiments were carried out at each operational $\mathrm{pH}(4,7$, and 9) in mesophilic conditions $\left(35^{\circ} \mathrm{C}\right)$ and manually shacked once per day. These $\mathrm{pH}$ conditions were chosen to evaluate the possibility of inhibiting methanogenesis without affecting hydrolytic and fermentative activity. For all the cases, the inoculum to substrate ratio was 2 on a grams of volatile solids (g VS) basis. Anaerobic conditions were achieved by flushing each bottle with $\mathrm{N}_{2}$ to displace the air from the headspace before sealing the bottle with a rubber septa and aluminium cap. The methane yield from the inoculum was distinguished by performing a blank experiment on the inoculum alone. All experiments, including the blank experiment, were performed in triplicate.

For experiments at $\mathrm{pH} 7$, biogas production was evaluated by using 24 serum bottles (140-mL). Alkalinity was initially added as $1 \mathrm{~g}$ of $\mathrm{CaCO}_{3}$. The characterization of the liquid phase throughout the experimental time was carried out by removing 2 serum bottles each day (destructive assays). The biogas production was quantified in all the remaining bottles through the pressure increase by using a manometer (Cole-Parmer Instrument Co Model 15.00 psig).

For experiments at $\mathrm{pH} 4$ and 9, biogas production and composition were monitored by using serum bottles (140-mL) in triplicate. In parallel to the serum bottles, effluent characterization was carried out at the same experimental conditions through 1-L glass reactors. The use of 1-L glass reactors was carried out to facilitate the measurement and correction, if necessary, of the operational $\mathrm{pH}$ during the experiments at $\mathrm{pH} 4$ and 9 . The operational $\mathrm{pH}$ was daily monitored and corrected, if necessary, at each reactor (including the serum bottles) by adding $0.1 \mathrm{M} \mathrm{HCl}$ or $0.1 \mathrm{M} \mathrm{NaOH}$ solutions as necessary. Samples from the 1-L digesters were daily taken to monitor the solubilisation of the wasted strawberry and 
the accumulation of VFA. Alkalinity was only added as $1 \mathrm{~g}$ of $\mathrm{CaCO}_{3}$ to the batch operating at $\mathrm{pH} 9$.

\subsection{Analytical techniques}

The characterization of the anaerobic inoculum, wasted strawberry and the effluents from the anaerobic digesters were carried out in triplicate according to the analytical techniques described as followed. Total solids (TS, $\mathrm{g} / \mathrm{kg}), \mathrm{VS}(\mathrm{g} / \mathrm{kg})$ content and $\mathrm{pH}$ were performed using standards methods (APHA, 2005). Soluble chemical oxygen demand (sCOD, $\mathrm{mgO}_{2} / \mathrm{L}$ ) was determined using COD cell test (ranges $25-1500 \mathrm{mg} / \mathrm{l}$ and $500-10000$ $\mathrm{mg} / \mathrm{L}$, Merck) and measured in a spectrophotometer (Spectroquant ${ }^{\circledR}$ Prove 300) at $620 \mathrm{~nm}$. Soluble phenols concentration was determined by the Folin-Ciocalteau method (García et al., 2016). Individual VFA $\left(\mathrm{C}_{2}-\mathrm{C}_{7}\right)$ were analysed using gas chromatography (Agilent Technologies 7890A GC System, CA, USA). All the soluble determinations were carried out after filtration using $0.22 \mu \mathrm{m}$ pore size filters. Ellagic acid was analysed in negative ESI mode using a modified method published by Yan et al. (2014). Individual bioactive compounds including anthocyanins, i.e. cyanidin 3-glucoside, pelargonidin 3-glucoside, and cyanidin glucuronide; and other phenolics, i.e. p-coumaric acid, quercetin glucuronide/quercetin hexoside, kaempferol glucuronide/kaempferol hexoside, isorhamnetin, and ferulic acid; were analysed using a modified method published by Gasperotti et al. (2015) by liquid chromatography-mass spectrometry (LC-MS/MS, Shimadzu 8060). The anthocyanins were analysed in positive electrospray ionization mode, whereas the phenolics were analysed in negative electrospray ionization mode.

The biogas composition was determined at the end of each test with a gas chromatograph (Perkin Elmer, Clarus® 590 GC), equipped with serially connected columns (7' HayeSep N 60/80, 1/8”'Sf and 9' Molecular Sieve 13x 45/60, 1/8”'Sf) and a thermal conductivity detector. 


\subsection{Data analysis}

The energy efficiency of the proposed method (fermentation at $\mathrm{pH} 4$ ) was evaluated by comparing its specific energy consumption with those obtained applying a high-temperature thermal treatment, which is the alternative extraction method reported in the literature for phenols extraction from strawberry waste (Fermoso et al., 2018; Rodríguez-Gutiérrez et al., 2019). The specific energy consumption was defined as the consumed energy per g gallic acid separated in the liquid phase (see Figure 1). The energy consumed was expressed as equivalent $\mathrm{kJ}$ by multiplying the consumed electricity and thermal energy by a factor of 2.6 and 1.1 respectively (Ryu \& Shin, 2013). All assumptions for the mass and energy balances are listed below:

- Data from the serum bottle and 1L experiments section was used in the mass and energy balances for both extraction strategies (Table 1).

- The enhanced extraction of phenolic compounds observed in the experiments was applied in the efficiency analysis.

- The electricity consumption included the energy requirement for pumping, $1800 \mathrm{~kJ} / \mathrm{m}^{3}$, and stirring, $300 \mathrm{~kJ} /\left(\mathrm{m}^{3}\right.$. day) (Ferrer et al., 2009). The thermal energy necessary to increase the temperature of the substrate to the operational temperature of $35^{\circ} \mathrm{C}$ was calculated assuming a heat capacity of $4.18 \mathrm{~kJ} / \mathrm{kg} / \mathrm{K}$ for the waste (Ferrer et al., 2009). To compensate thermal losses in the fermenter, an extra $10 \%$ was added to the theoreticalcalculated value of required thermal energy (He et al., 2019). $20{ }^{\circ} \mathrm{C}$ was fixed as the average environmental temperature.

- In the thermal extraction method, the strawberry waste is thermally treated for 1 hour by the injection of steam at $150{ }^{\circ} \mathrm{C}$ and $5 \mathrm{~kg} / \mathrm{cm}^{2}$ (Rodríguez-Gutiérrez et al., 2019). The mass ratio steam:waste was set on 1 (Trujillo-Reyes et al., 2019). All the steam added during the thermal pre-treatment is considered to remain in the strawberry stream. 
Thermal energy recovery of $80 \%$ was imposed, reducing the thermal energy consumption (Franchetti, 2013). According to the data reported by Rodríguez-Gutiérrez et al. (2019), the amount of soluble phenols after the thermal treatment was duplicated respect to that in the untreated strawberry waste.

- Separation stage. A centrifuge was used for separation. The mass ratio liquid-phase:solidphase was set to 80:20 after centrifugation. The electricity consumption for centrifugation was $2 \mathrm{kWh}$ per ton of treated-waste stream (Kookos et al., 2019).

\subsection{Data processing and statistical analysis}

The data processing and statistical analysis (means and standard deviations) were carried out using SigmaPlot ${ }^{\mathrm{TM}}$ version 11.0 and Microsoft Excel 2010VR software. The tstudent test $(\mathrm{p}=0.05)$ was used as statistics analysis to evaluate the significant differences in the concentrations of individual anthocyanins and phenolic compounds throughout the experimental time in the experiments at $\mathrm{pH} 4$.

\section{RESULTS AND DISCUSSION}

\subsection{Methane production}

As expected, the fixation of the operational $\mathrm{pH}$ to 4 resulted in the almost total inhibition of methane production (Figure 2), while the anaerobic digestion of wasted strawberry at $\mathrm{pH} 7$ resulted in the highest final methane yield, reaching a value up to $353 \pm$ $10 \mathrm{~mL} \mathrm{CH}_{4} / \mathrm{g}$ VS. This value is within the range described by Trujillo-Reyes et al. (2019), which reported methane yields from 324 to $391 \mathrm{~mL} \mathrm{CH}_{4} / \mathrm{g}$ VS for the anaerobic digestion of strawberry waste at mesophilic conditions.

The methane yield at $\mathrm{pH} 9$ reached a final value of $215 \pm 10 \mathrm{~mL} \mathrm{CH}_{4} / \mathrm{g} \mathrm{VS}$. However, the time required to achieve this yield was significantly lower than at $\mathrm{pH} 7$ (Figure 2). The high methane production rate can be a consequence of the enhancement of the hydrolysis 
activity due to the alkaline operational $\mathrm{pH}$ since this stage is usually the rate-limiting for the anaerobic digestion of organic solids (Ortega et al., 2008). Alkaline $\mathrm{pH}$ has been reported to enhance the hydrolysis rate by enhancing the activity of some enzymes involved in the disintegration and solubilization of proteins and carbohydrates (Fang et al., 2020; Jie et al., 2014). Although the methane yield coefficient was around $40 \%$ lower than that obtained at $\mathrm{pH} 7$, the methanogenesis was only partially inhibited. Methanogenesis at $\mathrm{pH} 9$ is rarely reported (Zhang et al., 2009), but there are some cases in literature reporting methane production at $\mathrm{pH} 9$ (Cabrera et al., 2019). Methanogenesis in the present study at pH 9 might be explained by the variation in the operational $\mathrm{pH}$ (Figure 3), which allowed the partial conversion of the soluble compounds into methane before the $\mathrm{pH}$ corrections. Contrary to this, maintaining the operational $\mathrm{pH}$ at 4 throughout the experimental time (Figure 3 ) did not require adding any extra reagents (data not shown) due to the acidic character of the wasted strawberry (Table 1).

The biogas composition at the end of the experiment varied depending on the operational $\mathrm{pH}$ (Table 2). The biogas at $\mathrm{pH} 7$ was composed of $71.87 \pm 0.24 \%$ of $\mathrm{CH}_{4}$ and $28.13 \pm 0.19 \%$ of $\mathrm{CO}_{2}$ (Table 2). The high methane production and methane content in the biogas at $\mathrm{pH} 7$ was in line with the $\mathrm{pH}$ of the reactors, which fell within the optimal values for the methanogenic activity, i.e. 6.6-7.8 (Yuan et al., 2011) (Figure 3). At pH 4 the low amount of biogas that was produced had a low percentage of methane as well as hydrogen, showing that methanogenesis and particularly hydrogenotrophic methanogenesis was inhibited in the proposed controlled process (Sivagurunathan et al., 2016).

\subsection{Accumulation of soluble matter and VFA}

The concentration of sCOD did not significantly vary in the reactors operated at $\mathrm{pH} 4$ (Figure 4a). After an initial decrease from $8575 \pm 50 \mathrm{mg} \mathrm{O}_{2} / \mathrm{L}$ to $6680 \pm 50 \mathrm{mg} \mathrm{O} / \mathrm{L}$, the sCOD gradually increased up to values around $9000 \mathrm{mg} \mathrm{O}_{2} / \mathrm{L}$. The concentration of VFA 
followed a similar trend to sCOD. The mean ratio VFA/sCOD was $0.17 \pm 0.07$, indicating that most of the soluble organic matter was not degraded to VFA. Despite this low ratio value, the acidogenic activity was not totally inhibited with the VFA concentration increasing from $402 \pm 40 \mathrm{mg} \mathrm{O}_{2} / \mathrm{L}$ up to $2220 \pm 210 \mathrm{mg} \mathrm{O}_{2} / \mathrm{L}$ (Figure 4a). At this operational $\mathrm{pH}$, the VFA mixture was mainly composed of acetic acid, with butyric acid being the next most prominent product in the liquid phase (Figure 5a). The presence of butyric acid has been previously related to the inhibition of the acetoclastic activity at high concentration of sugars, which might result in the accumulation of long-chain fatty acids (van den Heuvel et al., 1988).

At $\mathrm{pH} 7$, the sCOD decreased from $8575 \pm 50 \mathrm{mg} \mathrm{O}_{2} / \mathrm{L}$ to $1800 \pm 55 \mathrm{mg} \mathrm{O}_{2} / \mathrm{L}$, in line with the high production of methane described in the previous section (Figure $4 \mathrm{~b}$ ). The composition of the sCOD strongly varied from day 0 to 1 , where most of the sCOD was composed of VFA. The mean ratio of VFA/sCOD remained at $0.79 \pm 0.06$ after day 1 (Figure 4b). This ratio reflects rapid conversion by acidogenic bacteria of soluble compounds in the wasted strawberry into VFA, i.e. around $70 \%$ of the soluble organic matter in the strawberry corresponds to sugars, which are quickly metabolized (Trujillo-Reyes et al., 2019). Acetic and propionic acid were the two most abundant VFA compounds, reaching maximum concentrations of $2425 \pm 78 \mathrm{mg} / \mathrm{L}$ and $1562 \pm 27 \mathrm{mg} / \mathrm{L}$, respectively, at day 1 (Figure 5b). After day 4, the concentration of VFA was almost undetectable, indicating that the methanogenic activity was higher than the VFA formation (Figure 5b).

The reactors operated at $\mathrm{pH} 9$ showed increases and decreases of the sCOD and VFA throughout the experimental time (Figure 5c) that matched the variations of the $\mathrm{pH}$ (Figure 3). This behaviour could be due to the changes in accumulation ( $\mathrm{pH}$ decrease) and consumption (pH adjustment) of acidic compounds (Figure 3). As can be seen in Figure 4c, the sCOD decreased during the first 3 days of operation, coinciding with the production of 
methane (Figure 2). After day 3, the methane production was effectively inhibited and, hence, the concentration of sCOD increased up to values around 7500-7700 mg $\mathrm{O}_{2} / \mathrm{L}$. Most of the sCOD corresponded to VFA, with the VFA/sCOD ratio reaching $0.95 \pm 0.02$ at the end of the experiment (Figure 4c). The sum of the sCOD and the methane yield, expressed as COD, reached a value close to $1 \mathrm{~g} \mathrm{COD/g} \mathrm{COD}$ added at the end of the experiment. This behaviour indicated that if methanogenesis could be effectively stopped, the operation at $\mathrm{pH} 9$ could improve the solubilisation of the wasted strawberry and the accumulation of VFA. Acetic acid was the main VFA in the digesters, followed by propionic acid, reaching concentrations up to $3588 \pm 14 \mathrm{mg} / \mathrm{L}$ and $872 \pm 2 \mathrm{mg} / \mathrm{L}$, respectively (Figure $5 \mathrm{c}$ ). Other acids were also present at the end of the experimental time, such as the iso-butyric acid $(291 \pm 5 \mathrm{mg} / \mathrm{L})$, butyric acid (206 $\pm 2 \mathrm{mg} / \mathrm{L})$, iso-valeric acid $(526 \pm 6 \mathrm{mg} / \mathrm{L})$, and valeric acid $(78 \pm 1 \mathrm{mg} / \mathrm{L})$

(Figure 5c). The distribution of the individual VFA was very similar to that described by Li et al. (2017) for the fermentation at pH 9 of primary sludge. These authors reported that the dominance of the acetic acid can be explained because the other VFAs can be easily converted to acetic acid through different metabolic pathways, and, at the same time, it is not being degraded into methane.

\subsection{Accumulation of bioactive compounds}

The concentration of total soluble phenolic compounds was monitored throughout the experimental time at the different operational $\mathrm{pH}$ conditions (Figure 6). The operation at $\mathrm{pH} 7$ resulted in an initial degradation of the soluble phenols, decreasing from $124 \pm 3 \mathrm{mg}$ gallic acid/L to $70 \pm 6 \mathrm{mg}$ gallic acid/L after 2 days of operation. Subsequently, the soluble phenol concentration gradually increased up to $114 \pm 1 \mathrm{mg}$ gallic acid/L at day 7 of operation (Figure 6). This accumulation may be due to the decrease in degradation and ongoing solubilisation of this phenolic compound. A similar process was described by Serrano et al. (2019) for the 
anaerobic digestion of olive mill solid waste, where most of the soluble phenols were degraded whereas vanillin accumulated in the experiments.

In contrast to the results observed at $\mathrm{pH} 7$, the concentration of soluble phenolic compounds doubled at $\mathrm{pH} 9$ and triplicated at $\mathrm{pH} 4$ in respect to the initial concentration in the reactors. The high concentrations of phenolic compounds at $\mathrm{pH} 4$ shows that this $\mathrm{pH}$ avoids the conversion of the soluble phenols to VFA. This accumulation of phenolic compounds is even higher than the obtained with thermal treatments of strawberry extrudate, where the solubilisation percentage were doubled after 1 hour at $150{ }^{\circ} \mathrm{C}$, increasing from around 3000 to $6000 \mathrm{mg}$ gallic acid/L (Rodríguez-Gutiérrez et al., 2019).

The concentration of individual anthocyanins and phenolic compounds were determined at $\mathrm{pH} 4$ and different operation times. As can be seen, the concentration in the reactor was always significantly lower than the determined in the wasted strawberry (Table 3). The low concentrations at the first sampling time $(0.04 \mathrm{~d})$ indicated that most of the compounds initially in the wasted strawberry were rapidly degraded in the reactors at $\mathrm{pH} 4$. However, during the reactor operation, the concentrations of pelargonidin 3-glucoside and pcoumaric acid showed a significant increase from $0.04 \mathrm{~d}$ to $1.01 \mathrm{~d}(\mathrm{p}=0.157$ and $\mathrm{p}=0.058$, respectively) (Table 3), showing that the acidogenic fermentation was able to release these compounds from the wasted strawberry. The increase in the concentration of p-coumaric acid can be directly related with the operation at $\mathrm{pH} 4$ since previous studies showed that $\mathrm{p}$ coumaric acid can be degraded at neutral pH (Borja et al., 1997; Serrano et al., 2017). Other bioactive compounds such as the ellagic acid and quercetin decreased with the operation time, indicating that the proposed acidogenic fermentation would not be a suitable method for their accumulation due to their high biodegradability. The ellagic acid has been reported to be easily biodegraded by anaerobic microorganisms, leading to the production of bioactive metabolites called urolithins (Muthukumaran et al., 2017). The accumulation of the analysed 
bioactive compounds was markedly lower than the increase in the concentration of soluble phenol concentration (Figure 6), showing that solubilisation was predominant over the production of secondary phenolic metabolites.

\subsection{Energetic efficiency comparison}

As can be seen in Table 4, the proposed method for phenol extraction, fermentation at $\mathrm{pH} 4$ had a higher energy efficiency as compared with the alternative method based on thermal treatment, reducing the specific energy consumption by around $96 \%$ compared to thermal extraction methods. This difference was mainly due to the high energy required for the production of steam during thermal treatment. Furthermore, the fermentation process solubilises a higher amount of phenols, i.e. $73 \%$ higher, with respect to that obtained in the case of using thermal treatment. Even more, the lower concentration of phenol in the liquid phase obtained from thermal treatment due to the condensed steam, $3.6 \mathrm{~g}$ gallic acid/L of liquid phase against $10.6 \mathrm{~g}$ gallic acid/L of liquid phase for fermentation, would increase the energy consumption for the downstream purification process. The fermentation process showed $119 \%$ higher electricity demand for stirring (Table 4), while double the energy requirement for centrifugation is half that of thermal treatment because of the water addition in the form of steam in the thermal process. In this sense, if the thermal energy consumption is not considered in the balance, due to the existence of a source of residual heat, the fermentation process would show a higher energy consumption. Therefore, although the energetic efficiency comparison in this study provides useful information to compare our proposed alternative for solubilisation of phenols against a conventional thermal method, further research to determine the energy required for purification in both treatments is also needed for an energetic evaluation.

\section{CONCLUSIONS}


The variation of the operational $\mathrm{pH}$ in the anaerobic digestion of wasted strawberry could be a sustainable method for controlling the accumulation of different target compounds. The operation at $\mathrm{pH} 7$ resulted in the highest final methane yield coefficient, whereas operation at $\mathrm{pH} 9$ favoured the accumulation of VFA, mainly acetic acid. Biogas production was inhibited at $\mathrm{pH} 4$ leading to an accumulation of soluble phenols up to 3 times the initial concentration in the reactors. This high phenol solubilization capacity, as well as the high energy efficiency, indicates that the acidogenic fermentation at $\mathrm{pH} 4$ it is a promising method for the recovery of phenols from wasted strawberry.

\section{ACKNOWLEDGMENTS}

This research work was funded by the University of Queensland through to the project UQECR1945969. The authors are very grateful to the Spanish Ministry of Economy and Competitiveness through the project CTM2017-83870-R. B. Alonso-Fariñas acknowledges the support of the mobility grant PP2019-532, granted by the University of Seville. The authors are very grateful to the companies Luvaberry ${ }^{\circledR}$ and SunnyRidge ${ }^{\circledR}$ for supplying the substrates.

\section{REFERENCES}

Baby, B., Antony, P., Vijayan, R., 2018. Antioxidant and anticancer properties of berries. Crit. Rev. Food. Sci. Nutr. 58(15), 2491-2507.

Borja, R., Alba, J., Banks, C.J., 1997. Impact of the main phenolic compounds of olive mill wastewater (OMW) on the kinetics of acetoclastic methanogenesis. Process Biochem. 32(2), 121-133.

Cabrera, F., Serrano, A., Torres, Á., Rodriguez-Gutierrez, G., Jeison, D., Fermoso, F.G., 2019. The accumulation of volatile fatty acids and phenols through a $\mathrm{pH}$-controlled fermentation of olive mill solid waste. Sci. Total Environ. 657, 1501-1507. 
Fang, W., Zhang, X., Zhang, P., Wan, J., Guo, H., Ghasimi, D.S.M., Morera, X.C., Zhang, T., 2020. Overview of key operation factors and strategies for improving fermentative volatile fatty acid production and product regulation from sewage sludge. J. Environ. Sci. 87, 93-111.

FAOSTAT. 2018. http://www.fao.org/faostat/en/\#data/QC.

Fermoso, F.G., Serrano, A., Alonso-Fariñas, B., Fernández-Bolaños, J., Borja, R., RodríguezGutiérrez, G., 2018. Valuable Compound Extraction, Anaerobic Digestion, and Composting: A Leading Biorefinery Approach for Agricultural Wastes. J. Agr. Food Chem. 66(32), 8451-8468.

Ferrer, I., Serrano, E., Ponsá, S., Vázquez, F., Font, X., 2009. Enhancement of thermophilic anaerobic sludge digestion by $70^{\circ}$ pre-treatment: Energy considerations. J. Residuals Sci. Tech. 6(1), 11-18.

Franchetti, M., 2013. Economic and environmental analysis of four different configurations of anaerobic digestion for food waste to energy conversion using LCA for: A food service provider case study. J. Environ. Manage. 123, 42-48.

García, A., Rodríguez-Juan, E., Rodríguez-Gutiérrez, G., Rios, J.J., Fernández-Bolaños, J., 2016. Extraction of phenolic compounds from virgin olive oil by deep eutectic solvents (DESs). Food Chem. 197, 554-561.

Gasperotti, M., Masuero, D., Mattivi, F., Vrhovsek, U. 2015. Overall dietary polyphenol intake in a bowl of strawberries: The influence of Fragaria spp. in nutritional studies. J. Funct. Foods 18, 1057-1069.

Giampieri, F., Forbes-Hernandez, T.Y., Gasparrini, M., Alvarez-Suarez, J.M., Afrin, S., Bompadre, S., Quiles, J.L., Mezzetti, B., Battino, M., 2015. Strawberry as a health promoter: An evidence based review. Food Funct. 6(5), 1386-1398. 
Giampieri, F., Tulipani, S., Alvarez-Suarez, J.M., Quiles, J.L., Mezzetti, B., Battino, M., 2012. The strawberry: Composition, nutritional quality, and impact on human health. Nutr. 28(1), 9-19.

Girotto, F., Lavagnolo, M.C., Pivato, A., Cossu, R., 2017. Acidogenic fermentation of the organic fraction of municipal solid waste and cheese whey for bio-plastic precursors recovery - Effects of process conditions during batch tests. Waste Manage. 70, 71-80.

Gu, X.Y., Liu, J.Z., Wong, J.W.C., 2018. Control of lactic acid production during hydrolysis and acidogenesis of food waste. Bioresource Technol. 247, 711-715.

He, H., Ji, X., Xie, X., Ding, X., Wang, F., Ding, J., Hai, Z., Tang, R., 2019. Energy and economic evaluation of three generations of anaerobic reactors for starch wastewater treatment. Environ. Pollutants Bioavailab. 31(1), 252-260.

Jaster, H., Arend, G.D., Rezzadori, K., Chaves, V.C., Reginatto, F.H., Petrus, J.C.C., 2018. Enhancement of antioxidant activity and physicochemical properties of yogurt enriched with concentrated strawberry pulp obtained by block freeze concentration. Food Res. Int. 104, 119-125.

Jie, W., Peng, Y., Ren, N., Li, B., 2014. Volatile fatty acids (VFAs) accumulation and microbial community structure of excess sludge (ES) at different pHs. Bioresource Technol. 152, 124-129.

Kookos, I.K., Koutinas, A., Vlysidis, A., 2019. Life cycle assessment of bioprocessing schemes for poly(3-hydroxybutyrate) production using soybean oil and sucrose as carbon sources. Resour. Conserv. Recy. 141, 317-328.

Li, X., Peng, Y., Zhao, Y., Zhang, L., Han, B., 2017. Volatile fatty acid accumulation by alkaline control strategy in anaerobic fermentation of primary sludge. Environ. Eng. Sci. 34(10), 703-710. 
Muthukumaran, S., Tranchant, C., Shi, J., Ye, X., Xue, S.J., 2017. Ellagic acid in strawberry (Fragaria spp.): Biological, technological, stability, and human health aspects. Food Qual. Saf. 1(4), 227-252.

Ortega, L., Husser, C., Barrington, S., Guiot, S., 2008. Evaluating limiting steps of anaerobic degradation of food waste based on methane production tests. Water Sci. Technol. 57, 419-22.

Pan, Z., Qu, W., Ma, H., Atungulu, G.G., McHugh, T.H., 2012. Continuous and pulsed ultrasound-assisted extractions of antioxidants from pomegranate peel. Ultrason. Sonochem. 19(2), 365-372.

Qin, L., Chen, H., 2015. Enhancement of flavonoids extraction from fig leaf using steam explosion. Ind. Crop. Prod. 69, 1-6.

Rodríguez-Gutiérrez, G., Cardoso, J.C., Rubio-Senent, F., Serrano, A., Borja, R., FernándezBolaños, J., Fermoso, F.G., 2019. Thermally-treated strawberry extrudate: A rich source of antioxidant phenols and sugars. Innov. Food Sci. Emerg. Technol. 51, 186193.

Rubio-Senent, F., Rodríguez-Gutiérrez, G., Lama-Muñoz, A., Fernández-Bolaños, J., 2013. Phenolic extract obtained from steam-treated olive oil waste: Characterization and antioxidant activity. Food Sci. Technol. 54(1), 114-124.

Ryu, C., Shin, D., 2013. Combined heat and power from municipal solid waste: Current status and issues in South Korea. Energies, 6(1), 45-57.

Serrano, A., Fermoso, F.G., Alonso-Fariñas, B., Rodríguez-Gutierrez, G., FernandezBolaños, J., Borja, R., 2017. Olive mill solid waste biorefinery: High-temperature thermal pre-treatment for phenol recovery and biomethanization. J. Cleaner Prod. 148, 314-323. 
Serrano, A., Fermoso, F.G., Alonso-Fariñas, B., Rodríguez-Gutiérrez, G., López, S., Fernandez-Bolaños, J., Borja, R., 2019. Performance evaluation of mesophilic semicontinuous anaerobic digestion of high-temperature thermally pre-treated olive mill solid waste. Waste Manage. 87, 250-257.

Siles, J.A., Serrano, A., Martín, A., Martín, M.A., 2013. Biomethanization of waste derived from strawberry processing: Advantages of pretreatment. J. Cleaner Prod. 42, 190197.

Sivagurunathan, P., Kumar, G., Bakonyi, P., Kim, S.-H., Kobayashi, T., Xu, K.Q., Lakner, G., Tóth, G., Nemestóthy, N., Bélafi-Bakó, K., 2016. A critical review on issues and overcoming strategies for the enhancement of dark fermentative hydrogen production in continuous systems. Int. J. Hydrogen Energ. 41(6), 3820-3836.

Terefe, N.S., Kleintschek, T., Gamage, T., Fanning, K.J., Netzel, G., Versteeg, C., Netzel, M., 2013. Comparative effects of thermal and high pressure processing on phenolic phytochemicals in different strawberry cultivars. Innov. Food Sci. Emerg. Technol. $19,57-65$.

Trujillo-Reyes, Á., Cubero-Cardoso, J., Rodríguez-Gutiérrez, G., García-Martín, J.F., Rodríguez-Galán, M., Borja, R., Serrano, A., Fermoso, F.G., 2019. Extraction of phenolic compounds and production of biomethane from strawberry and raspberry extrudates. Biochem. Eng. J. 147, 11-19.

van den Heuvel, J.C., Beeftink, H.H., Verschuren, P.G., 1988. Inhibition of the acidogenic dissimilation of glucose in anaerobic continuous cultures by free butyric acid. Appl. Microbiol. Biotechnol. 29(1), 89-94.

Warner, D., Tzilivakis, J., Lewis, K., 2005. Sustainability of UK strawberry crop: Final report for Defra project HH3606. 
Wheatley, A., 1990. Anaerobic digestion: a waste treatment technology. Elsevier Applied Science. New York, NY, USA.

Wu, Y., Ma, H., Zheng, M., Wang, K., 2015. Lactic acid production from acidogenic fermentation of fruit and vegetable wastes. Bioresource Technol. 191, 53-58.

Yan, L., Yin, P., Ma, C., Liu, Y. 2014. Method development and validation for pharmacokinetic and tissue distributions of ellagic acid using ultrahigh performance liquid chromatography-tandem mass spectrometry (UPLC-MS/MS). Molecules 19(11), 18923-18935.

Yuan, X., Shi, X., Dalei, Z., Qiu, Y., Guo, R., Wang, L., 2011. Biogas production and microcystin biodegradation in anaerobic digestion of blue algae. Energ. Environ. Sci. 4, 1511-1515.

Zhang, P., Chen, Y., Zhou, Q., 2009. Waste activated sludge hydrolysis and short-chain fatty acids accumulation under mesophilic and thermophilic conditions: Effect of $\mathrm{pH}$. Water Res. 43(15), 3735-3742.

Zhang, Y., Seeram, N.P., Lee, R., Feng, L., Heber, D., 2008. Isolation and identification of strawberry phenolics with antioxidant and human cancer cell antiproliferative properties. J. Agri. Food Chem. 56(3), 670-675. 


\section{Figure captions}

Figure 1. Alternative processes for phenols extraction from strawberry waste: A) Fermentation at $\mathrm{pH}=4$, and $\mathrm{B}$ ) Thermal treatment 1 hour at $150{ }^{\circ} \mathrm{C}$.

Figure 2. Accumulated methane yield coefficient ( $\left.\mathrm{mL} \mathrm{CH}_{4} / \mathrm{g} \mathrm{VS}\right)$ at $\mathrm{pH} 7,4$ and 9.

Figure 3. Measured $\mathrm{pH}$ over time on the reactors operated at $\mathrm{pH} 7, \mathrm{pH} 4$ and $\mathrm{pH} 9$.

Figure 4. Concentration of soluble chemical oxygen demand (sCOD) and volatile fatty acids (VFA) over time on the reactors operated at (a) $\mathrm{pH} 4$, (b) $\mathrm{pH} 7$, and (c) $\mathrm{pH} 9$.

Figure 5. Characterization of volatile fatty acids (VFA) produced over the experimental time at (a) $\mathrm{pH} 4$, (b) $\mathrm{pH} 7$, and (c) $\mathrm{pH} 9$.

Figure 6. Concentration of soluble phenols over time on the reactors operated at $\mathrm{pH} 4, \mathrm{pH} 7$ and $\mathrm{pH} 9$. 
Figure 1.

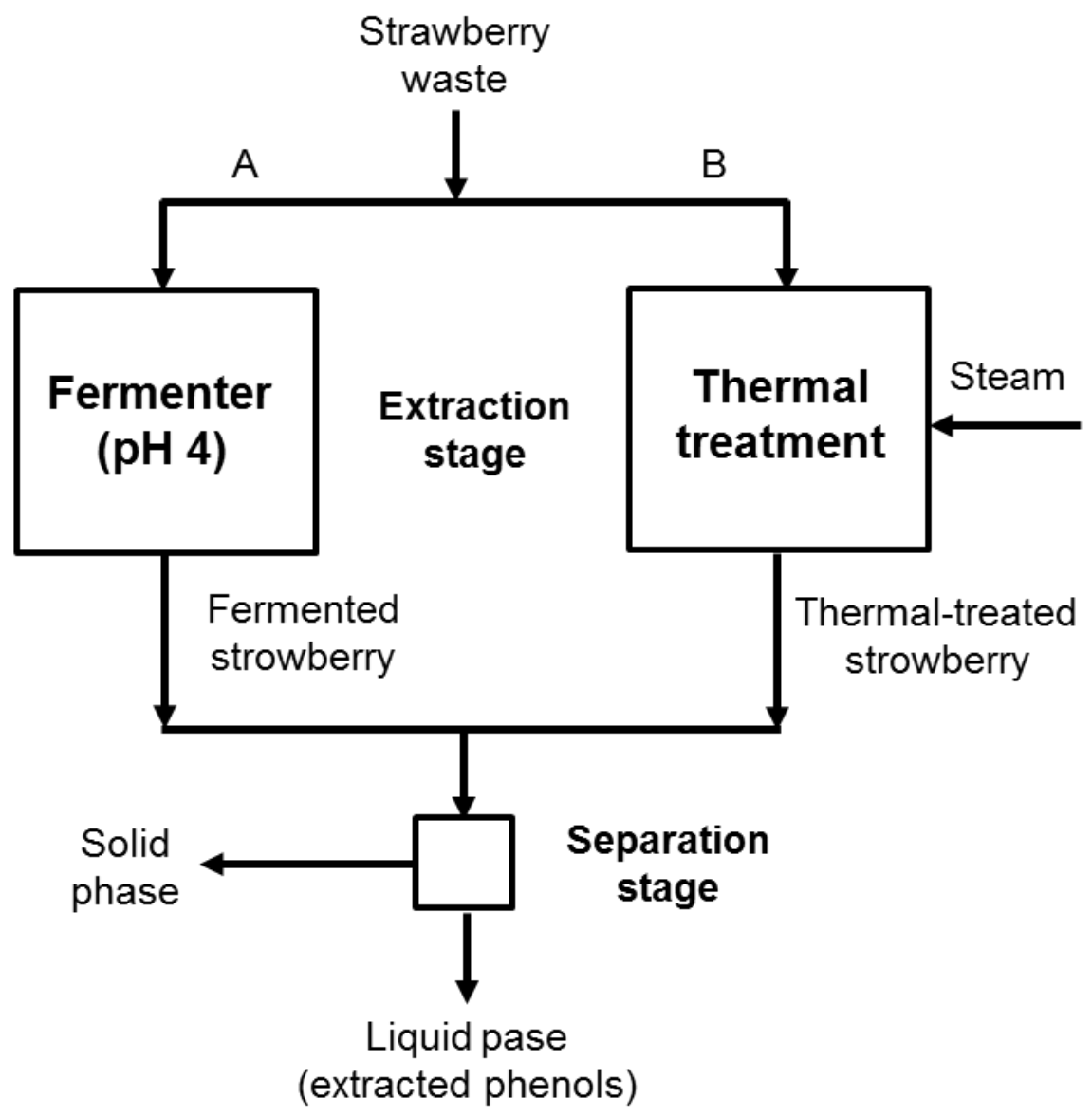


Figure 2.

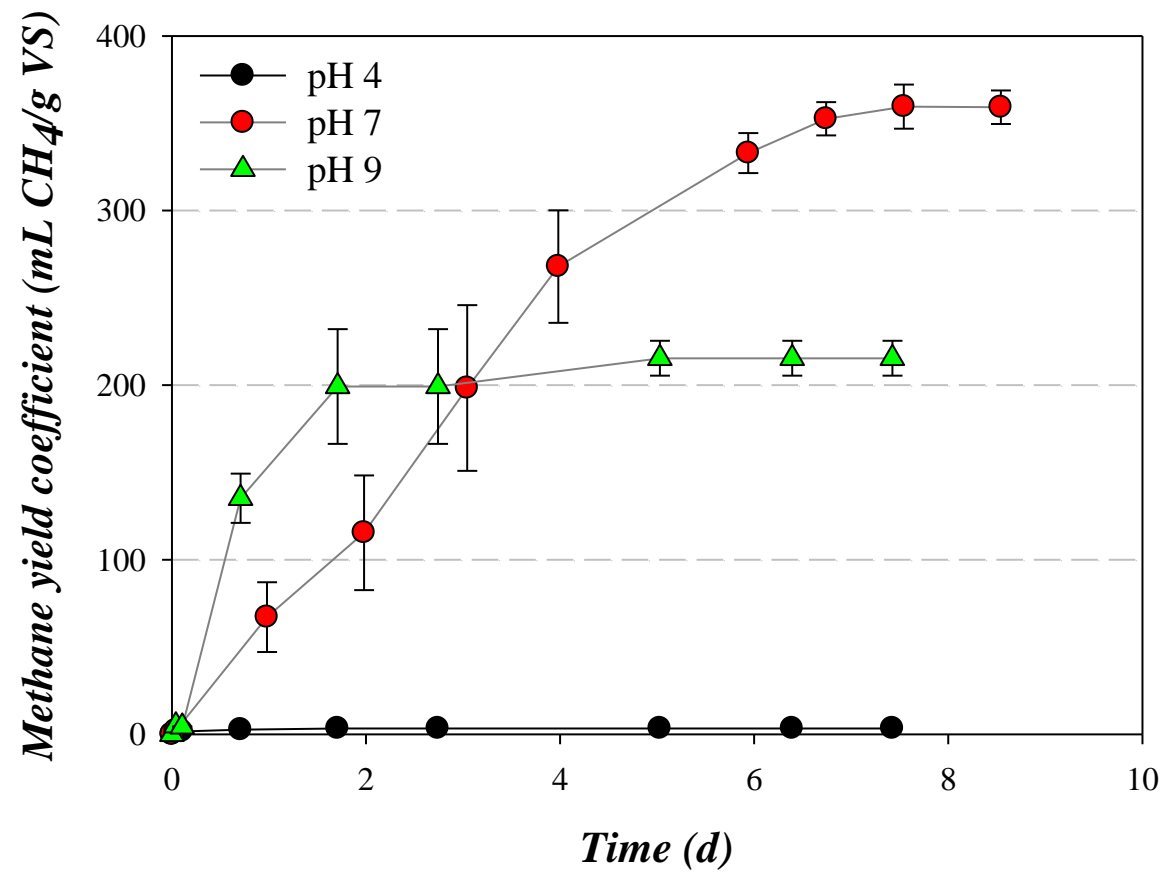


Figure 3.

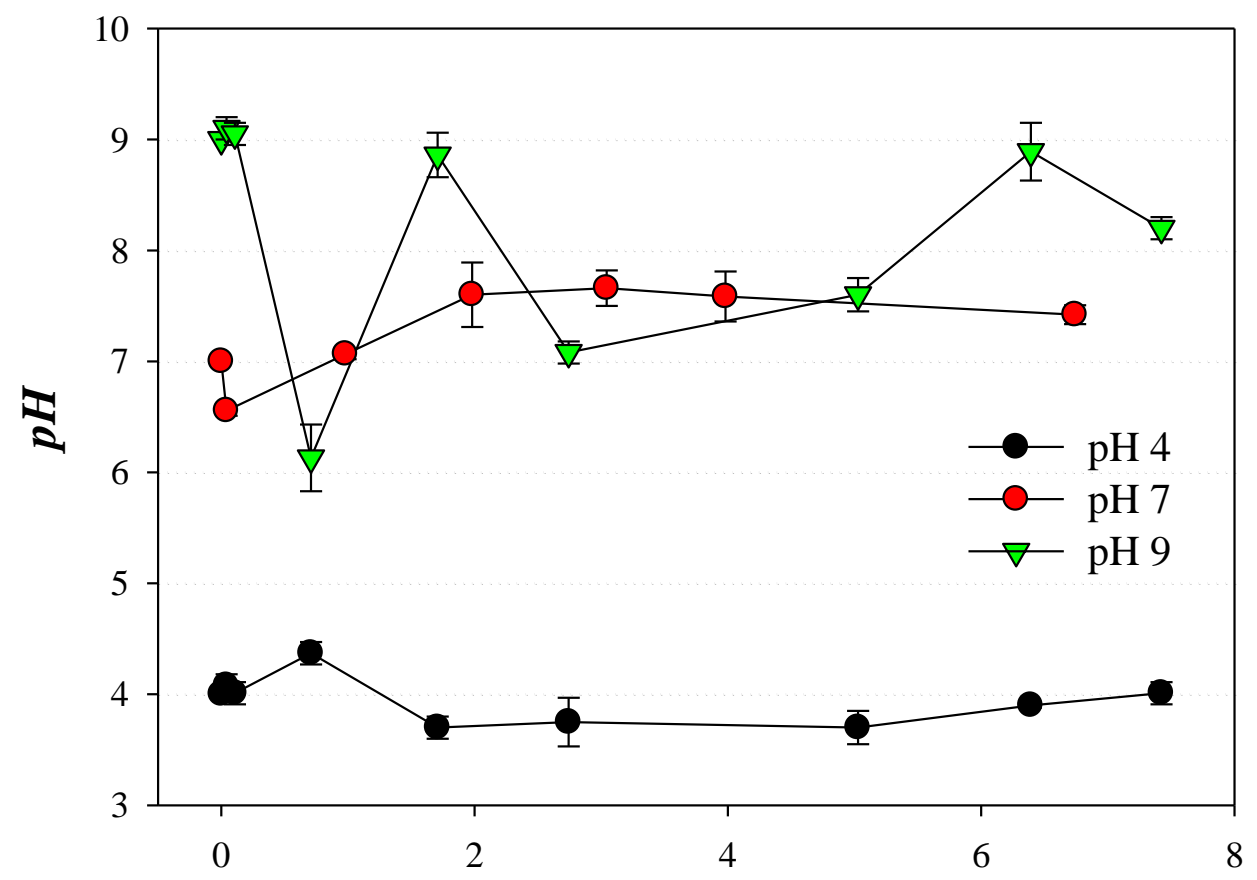

Time (d) 
Figure 4.

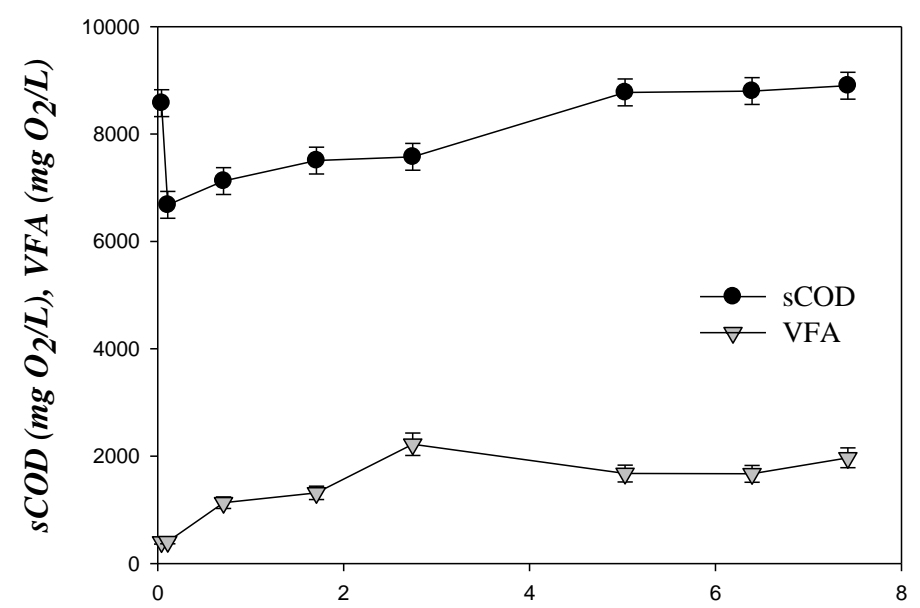

A)

Time (d)

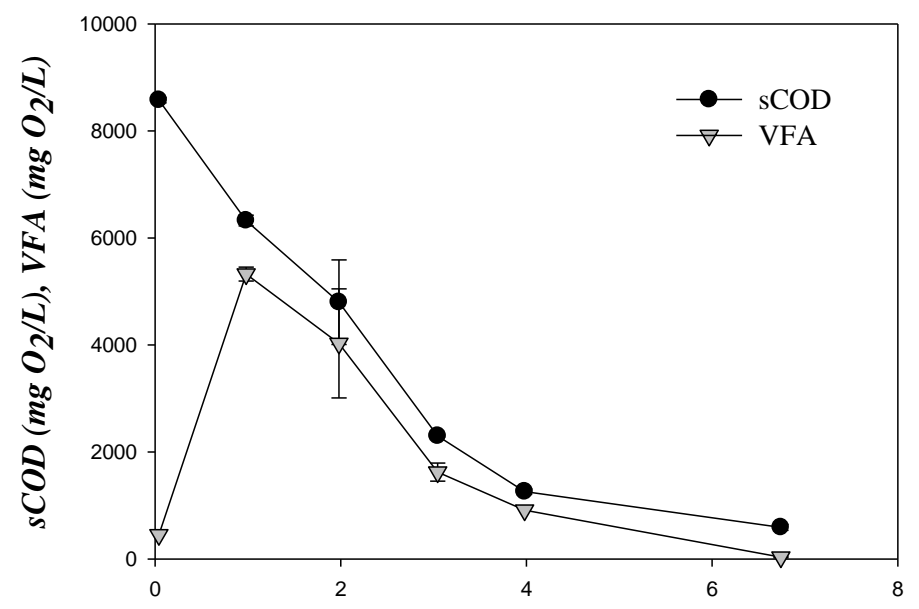

B)

Time (d)

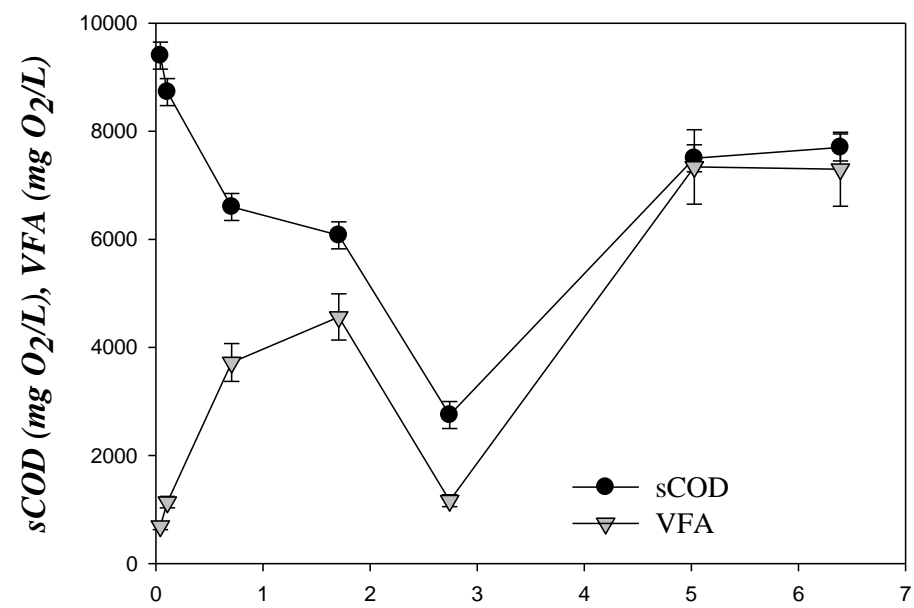

C)

Time (d) 


\section{Figure 5.}

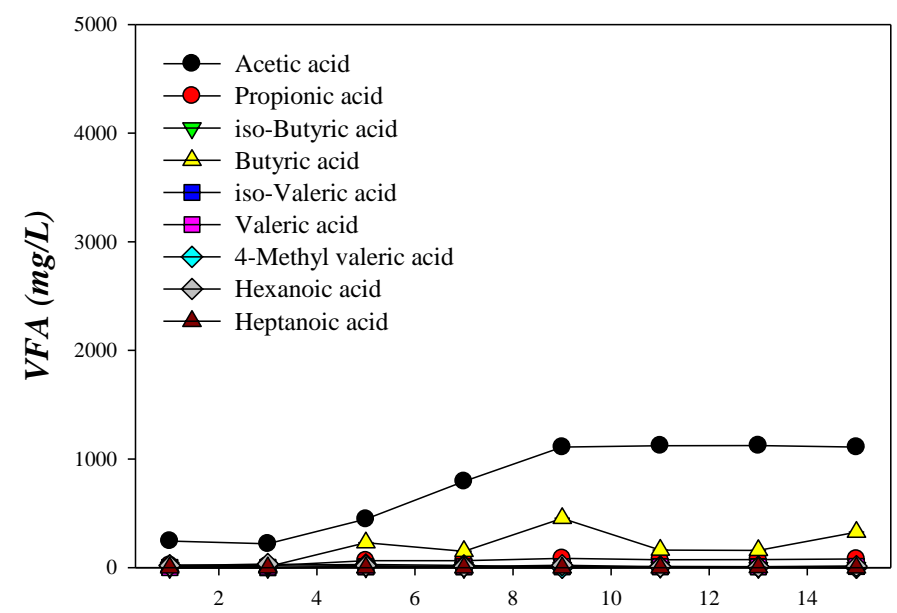

A)

Time (d)

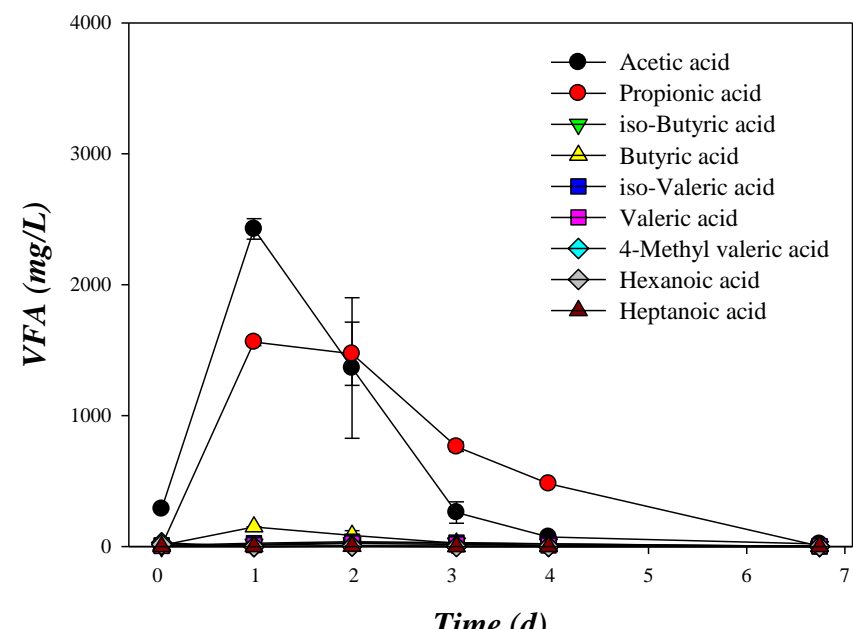

B)

Time (d)

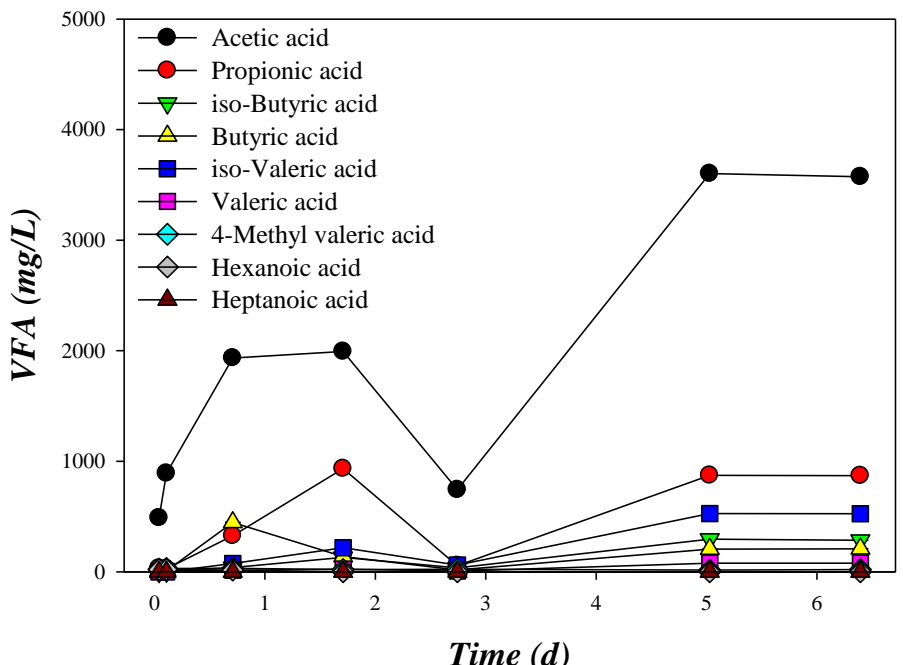

C)

Time (d) 
Figure 6.

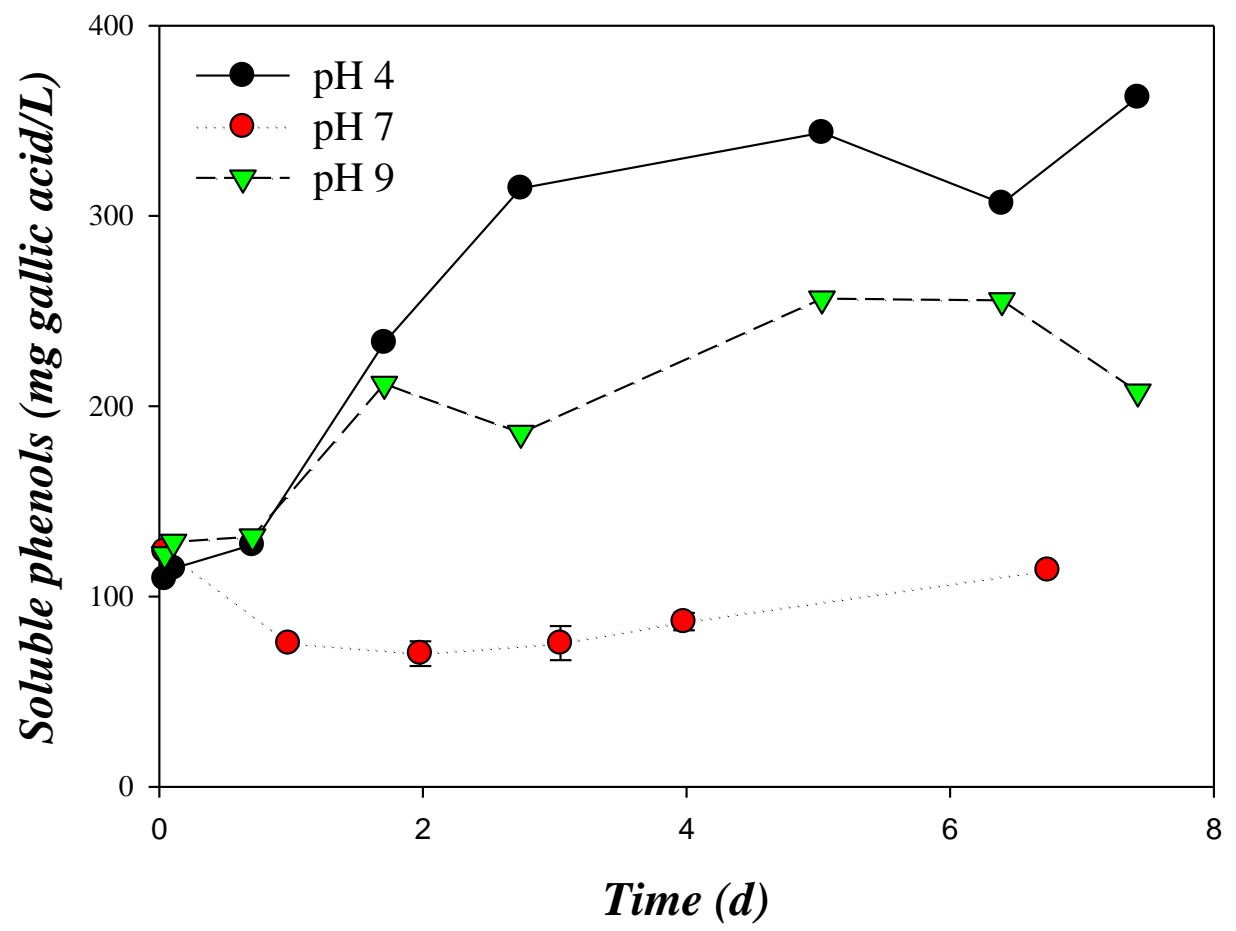


Table 1. Analytical characterization of the wasted strawberry waste and the inoculum (wet weight basis)

\begin{tabular}{|c|c|c|}
\hline & Wasted strawberry & Inoculum \\
\hline pH & $3.5 \pm 0.5$ & $7.3 \pm 0.1$ \\
\hline Moisture (\%) & $91.51 \pm 0.56$ & $95.17 \pm 2.96$ \\
\hline $\mathrm{COD}\left(\mathrm{g} \mathrm{O}_{2} / \mathrm{kg}\right)$ & $110.5 \pm 2.4$ & - \\
\hline $\mathrm{COD}_{\text {soluble }}\left(\mathrm{mg} \mathrm{O}_{2} / \mathbf{k g}\right)$ & $99,400 \pm 3650$ & $525 \pm 25$ \\
\hline TS (g/kg) & $84.9 \pm 0.6$ & $48.3 \pm 1.5$ \\
\hline FS $(g / k g)$ & $7.1 \pm 1.7$ & $8.3 \pm 0.2$ \\
\hline VS (g/kg) & $77.8 \pm 1.7$ & $40.1 \pm 1.3$ \\
\hline Soluble phenols (mg Gallic acid/kg) & $1532 \pm 78$ & $<$ D.L. \\
\hline
\end{tabular}

D.L., Detection limit; -, not determined 
Table 2. Biogas composition (in \%) obtained at each operational $\mathrm{pH}$ at the end of the experimental time.

\begin{tabular}{lccc} 
& pH 7 & pH 4 & pH 9 \\
\cline { 2 - 4 } $\mathbf{C H}_{\mathbf{4}}$ & $71.87 \pm 0.24$ & $1.77 \pm 0.77$ & $58.24 \pm 3.98$ \\
$\mathbf{C O}_{2}$ & $28.13 \pm 0.19$ & $13.04 \pm 1.09$ & $1.81 \pm 0.82$ \\
$\mathbf{N}_{2}$ & $<$ D.L. & $80.52 \pm 0.23$ & $37.23 \pm 4.38$ \\
$\mathbf{O}_{2}$ & $<$ D.L. & $4.68 \pm 0.01$ & $2.7 \pm 0.10$ \\
$\mathbf{H}_{2}$ & $<$ D.L. & $<$ D.L. & $<$ D.L. \\
$\mathbf{H}_{2} \mathbf{S}$ & $<$ D.L. & $<$ D.L. & $<$ D.L. \\
$\mathbf{C O}$ & $<$ D.L. & $<$ D.L. & $<$ D.L. \\
\hline D.L., Detection limit & & &
\end{tabular}


Table 3. Concentrations of individual anthocyanins, ellagic acid and phenolics (mg/L) obtained for the wasted strawberry and the reactors operated at $\mathrm{pH} 4$.

\begin{tabular}{|c|c|c|c|c|c|}
\hline & \multirow{2}{*}{$\begin{array}{c}\text { Wasted } \\
\text { strawberry }\end{array}$} & \multicolumn{4}{|c|}{ Running time (days) } \\
\hline & & 0.04 & 1.01 & 3.94 & 6.97 \\
\hline $\begin{array}{l}\text { Anthocyanins } \\
\text { strawberry) }\end{array}$ & & & & & \\
\hline \multirow[t]{2}{*}{ Cyanidin 3-glucoside } & $1.09 \pm 0.05$ & $<$ D.L. & $<$ D.L. & $<$ D.L. & $<$ D.L. \\
\hline & & $0.04 \pm$ & $1.03 \pm$ & $0.13 \pm$ & $0.06 \pm$ \\
\hline \multirow[t]{2}{*}{ Pelargonidin 3-glucoside } & $4.72 \pm 0.05$ & 0.01 & 0.24 & 0.01 & 0.01 \\
\hline & & & $0.06 \pm$ & & \\
\hline Cyanidin glucuronide & $1.59 \pm 0.05$ & $<$ D.L. & 0.01 & $<$ D.L. & $<$ D.L. \\
\hline \multirow[t]{2}{*}{ Total anthocyanins } & $7.40 \pm 0.15$ & $\begin{array}{c}0.04 \pm \\
0.01\end{array}$ & $\begin{array}{l}1.10 \pm \\
0.25\end{array}$ & $\begin{array}{c}0.13 \pm \\
0.01\end{array}$ & $\begin{array}{c}0.06 \pm \\
0.01\end{array}$ \\
\hline & & $0.42 \pm$ & $0.07 \pm$ & & \\
\hline Ellagic acid (mg/kg strawberry) & $6.10 \pm 0.05$ & 0.01 & 0.01 & $<$ D.L. & $<$ D.L. \\
\hline \multicolumn{6}{|l|}{$\begin{array}{l}\text { Other phenolics } \quad(\mathrm{mg} / \mathrm{kg} \\
\text { strawberry })\end{array}$} \\
\hline p-Coumaric acid & $\begin{array}{c}12.26 \pm \\
0.05\end{array}$ & $\begin{array}{c}0.06 \pm \\
0.01\end{array}$ & $\begin{array}{c}0.17 \pm \\
0.02\end{array}$ & $\begin{array}{c}0.04 \pm \\
0.01\end{array}$ & $\begin{array}{c}0.02 \pm \\
0.01\end{array}$ \\
\hline Quercetin glucuronide/quercetin & & $0.63 \pm$ & $0.53 \pm$ & $0.36 \pm$ & $0.28 \pm$ \\
\hline hexoside & $1.69 \pm 0.05$ & 0.01 & 0.01 & 0.02 & 0.02 \\
\hline Kaempferol & & $0.45 \pm$ & $0.51 \pm$ & $0.47 \pm$ & \\
\hline glucuronide/Kaempferol hexoside & $0.29 \pm 0.02$ & 0.01 & 0.03 & 0.01 & $<$ D.L. \\
\hline Isorhamnetin & $<$ D.L. & $<$ D.L. & $<$ D.L. & $<$ D.L. & $<$ D.L. \\
\hline Ferulic acid & $0.32 \pm 0.01$ & $<$ D.L. & $<$ D.L. & $<$ D.L. & <D.L. \\
\hline
\end{tabular}


Table 4. Energy efficiency comparison between fermentation and thermal treatment

\begin{tabular}{|c|c|c|c|}
\hline Extraction process & & Fermentation & Thermal treatment \\
\hline & & $(\mathbf{p H}=\mathbf{4})$ & $\left(150{ }^{\circ} \mathrm{C}-1 \mathrm{~h}\right)$ \\
\hline Thermal energy consumption & $\mathrm{kJ} / \mathrm{kg}$ waste & 63 & 2196 \\
\hline Electricity consumption & $\mathrm{kJ} / \mathrm{kg}$ waste & 35 & 16 \\
\hline Total equivalent energy consumption ${ }^{1}$ & Equivalent $\mathrm{kJ} / \mathrm{kg}$ waste & 159 & 2458 \\
\hline \multirow[t]{2}{*}{ Soluble phenols in liquid phase } & g gallic acid/kg waste & 8.5 & 4.9 \\
\hline & g gallic acid/L of liquid phase & 10.6 & 3.6 \\
\hline Specific energy consumption & Equivalent $\mathrm{kJ} / \mathrm{g}$ gallic acid & 19 & 502 \\
\hline
\end{tabular}

${ }^{1}$ Sum of thermal energy and electricity consumption after applying factors equals to 1.1 and 2.6 respectively 